\title{
Motorcycle-Related Traumatic Brain Injuries: Helmet Use and Treatment Outcome
}

\author{
Mathias Ogbonna Nnanna Nnadi, ${ }^{1}$ Olufemi Babatola Bankole, ${ }^{2}$ \\ and Beleudanyo Gbalipre Fente ${ }^{3}$ \\ ${ }^{1}$ Division of Neurosurgery, Department of Surgery, University of Calabar Teaching Hospital, Calabar, Nigeria \\ ${ }^{2}$ Neurosurgical Unit, Department of Surgery, Lagos University Teaching Hospital, Idi-Araba, Lagos, Nigeria \\ ${ }^{3}$ General Surgery Unit, Department of Surgery, Niger Delta University Teaching Hospital, Okolobiri, Bayelsa State, Nigeria
}

Correspondence should be addressed to Mathias Ogbonna Nnanna Nnadi; nnadimon@yahoo.com

Received 29 July 2014; Revised 2 March 2015; Accepted 5 March 2015

Academic Editor: Rose Du

Copyright (C) 2015 Mathias Ogbonna Nnanna Nnadi et al. This is an open access article distributed under the Creative Commons Attribution License, which permits unrestricted use, distribution, and reproduction in any medium, provided the original work is properly cited.

\begin{abstract}
Summary. With increasing use of motorcycle as means of transport in developing countries, traumatic brain injuries from motorcycle crashes have been increasing. The only single gadget that protects riders from traumatic brain injury is crash helmet. Objective. The objectives were to determine the treatment outcome among traumatic brain injury patients from motorcycle crashes and the rate of helmet use among them. Methods. It was a prospective, cross-sectional study of motorcycle-related traumatic brain injury patients managed in our center from 2010 to 2014. Patients were managed using our unit protocol for traumatic brain injuries. Data for the study were collected in accident and emergency, intensive care unit, wards, and outpatient clinic. The data were analyzed using Environmental Performance Index (EPI) info 7 software. Results. Ninety-six patients were studied. There were 87 males. Drivers were 65. Only one patient wore helmet. Majority of them were between 20 and 40 years. Fifty-three patients had mild head injuries. Favorable outcome among them was $84.35 \%$ while mortality was $12.5 \%$. Severity of the injury affected the outcome significantly. Conclusion. Our study showed that the helmet use by motorcycle riders was close to zero despite the existing laws making its use compulsory in Nigeria. The outcome was related to severity of injuries.
\end{abstract}

\section{Introduction}

The increasing use of motorcycles in commercial transportation in developing countries has led to explosion of their number in many countries [1-3]. In Nigeria, the trend is the same $[4,5]$. Increasing number of motorcycles was associated with increasing number of motorcycle crashes [1]. Per vehicle mile travelled, motorcycle riders have a 34-fold higher risk of death in a crash than people driving other vehicles and are 8 times more likely to be injured [6]. The use of helmet reduced head injuries among riders [7]. We studied motorcyclerelated traumatic brain injury patients in our center over a three-and-half-year period.

\section{Methods}

It was a prospective, descriptive, and cross-sectional study involving motorcycle-related traumatic brain injury patients managed in our center from August 2010 to January 2014. Patients were managed using our protocol for traumatic brain injuries.

2.1. Our Protocol. Patients were managed in accident and emergency using advanced trauma life support (ATLS) protocols (primary and secondary surveys). In primary surveys, patients were resuscitated ensuring patent airways and oxygen saturation of $95 \%$ and above. We used normal saline to maintain blood volume aiming at euvolemia and normotension. We gave adequate analgesia, antiepileptic drugs in posttraumatic seizures, and calm aggressive patients with chlorpromazine. Quick checks for other organ injuries that could be life threatening to patients were made. In secondary survey, we took detailed history and physical examination of patients. Glasgow Coma Scores after resuscitation of patients were assessed. Appropriate investigations were carried out 
based on needs and their affordability. Patients with severe traumatic brain injuries were admitted to intensive care unit while those with mild and moderate traumatic brain injuries were admitted to the wards. Patients with CT scan lesions not requiring surgery and those who could not afford CT scan were managed nonoperatively. Patients with lesions requiring surgery such as extradural, subdural, and intracerebral hematomas/contusions and depressed skull fractures had surgical care. Surgical procedures included craniotomy for acute extradural, acute subdural, and intracerebral hematomas/contusions, burr hole for subacute and chronic subdural hematomas, and craniectomy with primary bone fragment replacement or depressed bone elevation for depressed skull fractures. Associated injuries were managed by appropriate specialist units.

We gave broad spectrum antibiotics (to those who had open tissue injuries), multivitamins, high energy and high protein diet. The diet was constituted thus: $500 \mathrm{~mL}$ pap, two tablespoonsful of powdered milk, one tablespoonful of red oil, two tablespoonsful of soya bean powder, and one tablespoonful of crayfish powder. The diet was given five to six times daily via nasogastric tubes or orally. Their daily fluid requirements were calculated and factored into the fluid content of the diet. We used locally prepared diet because most of our patients could not afford Complan or Casilan and there was no functional dietetic unit in our hospital. On discharge, patients were followed up in the outpatient clinic and by phone calls when they failed to attend the clinic.

Data were collected using structured proforma which was part of our prospective data bank that was approved by our hospital's ethics and research committee. The biodata, position of patient at the time of crash (driver, passenger, or pedestrian), helmeted or not helmeted at the time of crash, severity of injury (using Glasgow Coma Score after resuscitation), and other clinical signs were collected in accident and emergency (A\&E) unit. Radiological findings were documented either in $\mathrm{A} \& \mathrm{E}$ or in the wards depending on the time the radiological imaging was done. The progress of the patients was documented in the wards. The functional outcome was determined using Glasgow Outcome Score (GOS) [8]. It classifies patients into 1 dead, 2 vegetative state, 3 severe disability, 4 moderate disability, and 5 good recovery. Four and five are regarded as good (favorable) functional outcome. The functional outcome was determined in outpatient clinic or by phone discussion (those who failed to attend the clinic) at three months after injury. The functional outcome three months after injury had been found to be the best predictor in the long term [9].

Motorcycle drivers, their passengers, and pedestrian hit by motorcycles were included in the study. Occupants of vehicles involved in crashes with motorcycles were excluded from the study.

2.2. Statistical Analysis. Data were analyzed using Environmental Performance Index (EPI) info 7 software (Center for Disease Control and Prevention, Atlanta, Georgia, USA: http://wwwn.cdc.gov/epiinfo/7/index.htm).

The visual band package was used for the analysis. The "frequency gadget" was used to analyze gender, helmet use,
TABLE 1: Age group frequency.

\begin{tabular}{lcc}
\hline Age group & Frequency & Percent $(\%)$ \\
\hline $0-<10$ & 3 & 3.13 \\
$10-<20$ & 14 & 14.58 \\
$20-<30$ & 24 & 25.00 \\
$30-<40$ & 30 & 31.25 \\
$40-<50$ & 17 & 17.71 \\
$50-<60$ & 5 & 5.21 \\
$60-<70$ & 3 & 3.13 \\
\hline Total & 96 & 100 \\
\hline
\end{tabular}

severity of injury, and mode of treatment. We used the "mean gadget" to determine the mean age of the patients. The ages were recoded in groups of tens and their frequency was determined also. "MxN/2X2 table" was used in analyzing two variables such as effect of severity of injury on outcome, while its advanced part was used in three variables such as position of patient, severity of injury, and outcome. With $95 \%$ confidence interval, $P<0.05$ was considered significant.

\section{Result}

There were 96 patients in the study. Males were 87 (90.32\%) while females were nine $(9.68 \%)$. Their ages ranged from three years to 69 years with mean age of 31.89 years. Majority of patients $(56.25 \%)$ were $20-40$ years (Table 1 ).

There were 65 motorcycle drivers, 22 passengers, and nine pedestrians. Of the 87 drivers/passengers $98.85 \%$ (86) did not wear helmet at the time of crash while $1.15 \%$ (one patient) wore helmet. Fifty-three patients had mild injuries, 29 had moderate injuries, and 23 had severe head injuries. Forty-four patients (45.83\%) did CT scan. Thirty-eight of them $(86.36 \%)$ had intracranial lesions while six patients had no intracranial lesion. There were multiple lesions in 18 patients' CT scans (Table 2). Eighty-one patients were managed nonoperatively, while 15 patients had surgical care. Three patients had burr holes for subacute/chronic subdural hematomas, six had craniotomy for acute subdural/epidural hematoma, three had craniectomy with bone fragments replacement for depressed skull fractures, and three had repair of scalp avulsions.

The overall favorable functional outcome was $84.38 \%$ and mortality was $12.5 \%$. Favorable outcome among those with severe head injury was $52.17 \%$. Severity of the injury significantly affected the outcome, $P=0.0002$ (Table 3 ). Presence of intracranial lesions did not significantly affect the outcome, $P=0.6178$.

\section{Discussion}

Ninety-six patients were studied and males formed $90.32 \%$ (87). The majority of patients were between 20 and 40 years. They were young men in their prime trying to make ends meet through commercial motorcycle driving since collar jobs were hard to come by in our country. With long traffic holdups in our city, many commuters use motorcycles as ways of circumventing the holdups. The patronage encourages 
TABLE 2: Intracranial lesion versus Glasgow Outcome Score.

\begin{tabular}{|c|c|c|c|c|c|c|}
\hline \multirow{2}{*}{ Intracranial lesions } & \multicolumn{6}{|c|}{ Glasgow Outcome Score (GOS) } \\
\hline & $1(\%)$ & $3(\%)$ & $4(\%)$ & $5(\%)$ & Total (\%) & $\geq 4(\%)$ \\
\hline Extradural & $0(0.00)$ & $0(0.00)$ & $0(0.00)$ & $4(100)$ & $4(100)$ & $4(100)$ \\
\hline Contusion & $2(8.00)$ & $1(4.00)$ & $1(4.00)$ & $21(84.00)$ & $25(100)$ & $22(88.00)$ \\
\hline DAI & $1(12.5)$ & $1(12.5)$ & $1(12.5)$ & $5(62.5)$ & $8(100)$ & $6(75.00)$ \\
\hline Edema & $0(0.00)$ & $0(0.00)$ & $0(0.00)$ & $3(100)$ & $3(100)$ & $3(100)$ \\
\hline Subdural & $3(27.72)$ & $1(9.09)$ & $1(9.09)$ & $6(54.55)$ & $11(100)$ & $7(63.64)$ \\
\hline Multiple & $3(16.67)$ & $1(5.56)$ & $2(11.11)$ & $12(66.67)$ & $18(100)$ & $14(77.78)$ \\
\hline
\end{tabular}

TABLE 3: Diagnosis versus GOS.

\begin{tabular}{|c|c|c|c|c|c|c|}
\hline \multirow{2}{*}{ Diagnosis } & \multicolumn{6}{|c|}{ Glasgow Outcome Score } \\
\hline & $1(\%)$ & $3(\%)$ & $4(\%)$ & $5(\%)$ & Total (\%) & $\geq 4(\%)$ \\
\hline Mild & $2(3.77)$ & $1(1.89)$ & $6(11.32)$ & $44(83.02)$ & $53(100)$ & $50(94.34)$ \\
\hline Moderate & $1(5.00)$ & $0(0.00)$ & $5(25.00)$ & $14(70.00)$ & $20(100)$ & $19(95.00)$ \\
\hline Severe & $9(39.13)$ & $2(8.70)$ & $2(8.70)$ & $10(43.48)$ & $23(100)$ & $12(52.17)$ \\
\hline Total & $12(12.50)$ & $3(3.13)$ & $13(13.54)$ & $68(70.83)$ & $96(100)$ & $81(84.38)$ \\
\hline
\end{tabular}

$P=0.0002$.

many young ones to join commercial motorcycle driving as source of living. These had been documented by many authors [10-17]. Low percentage of patients who could afford CT scan led credence to the level of income among the patients.

Of 86 drivers/passengers, only one patient (1.16\%) wore helmet. Nwadiaro et al. [14] in their study in north-central Nigeria found $100 \%$ not using helmet. Arosanyin et al. [18] in Zaria, Nigeria, found 16\% helmet use in their study. In Ilorin, Nigeria, Arosanyin [19] found 13.5\% helmet use. The reasons they found were cost of acquisition and weak enforcement of helmet laws. In Iribhogbe and Odai [20] study, they found that many motorcyclists complain of cost of helmet while many had helmets but refused to wear them due to "inconveniencies." In spite of overwhelming evidence that helmet use prevented head trauma [7, 21], there had been hostilities towards helmet use mainly due to cost, ignorance, drug use, and discomfort [10]. "In United States of America (USA) similar hostilities had been documented. In 1966, the congress mandated US Department of Transportation to withhold federal funds from states without mandatory helmet laws. In 1975 organization such as ABATE (A Brotherhood Against Totality Enactment) lobbied USA congress to repeal the mandatory helmet laws. Their reasons included reduced visibility, reduced hearing, and neck injuries. These were not validated by scientific evidence. Repeal of the law by the congress led many states to repeal their own [22]." An evidence based review of articles from 1990 to 2009 by Macleod et al. [23] in USA showed that the use of helmets decreased the overall death rate of motorcycle crashes when comparing helmeted with nonhelmeted patients; helmet decreased the incidence of lethal head injury in crashes compared to nonhelmeted ones; helmet decreased the severity of nonlethal head injury compared to nonhelmeted ones; helmet laws reduced mortality and head injuries in areas with the law compared with those without the law. The protective effect of helmet use was also found in the study across three cities in Europe (Hannover, Munich, and Glasgow) by Richter et al. [12]. In Italy, Latorre et al. [24] studied 736 injured riders and found $12 \%$ helmet use but the protective effect of helmet was significant. In Jamaica, opponents of helmet law said that crashes in developed countries were due to high speedways and well maintained roads unlike windy poor surfaced and congested local highways in their country where the speed was low. They claimed that the injuries in their roads would be less severe. Study carried out by Crandon et al. [10] in University of West Indies showed otherwise. In many developing countries high nonhelmet use had been documented by many authors [1,25-27]. These showed that low level of helmet use was not peculiar to our center but a global "disease." The fact that the only helmeted patient in our study had severe head injury was of note. Head injury had been found to be the leading cause of death even in helmeted riders [28]. It had also been deduced that helmet and the other safety equipment showed efficacy in reducing deaths or serious injuries, but they had not been sufficient for safe lives [29, 30]. It should be noted that obedience to traffic laws is complimentary to helmet use. The failure of drivers to comply with basic road safety legislation was the main cause of serious crashes in many series $[16,17,31-$ 33]. In Nigeria, Arosanyin et al. [18] found that, of the 344 commercial motorcyclists studied, $64 \%$ had driving license, $16 \%$ used helmet, $58.2 \%$ were aware of highway code, and $45 \%$ obeyed legal permissible passengers. Owoaje et al. [34] found zero rates of compliance with highway code. In Thailand, Siviroj et al. [35] found that, among 18,998 riders studied during Songkran festival, $44.2 \%$ had not been using helmet and $72.5 \%$ of passengers had not been using helmet. They also found that $75 \%$ agreed with the danger of nonhelmet use and $47.2 \%$ had been caught with the nonuse of a helmet before. They found that $83.7 \%$ had heard about road safety awareness campaign. Inasmuch as helmet use and safety laws are good, 
motorcycle rider education is also essential as this has been found to have positive effect on changing risky behavior of riders and motorcycle-related injuries in rural Thailand [36]. In Malaysia it was found that provision of exclusive lane for motorcycles reduced deaths by $60 \%$ [37].

Among our patients, the overall favorable functional outcome was $84.38 \%$ and mortality was $12.5 \%$. In the study of 344 patients with traumatic brain injury in Nepal, Agrawal et al. [38] found good recovery in $87.7 \%$ and mortality of $4.5 \%$. In Zaria, Nigeria, Muhammad [39] found mortality of $29 \%$ among the patients he studied. Hitimana et al. [40] found mortality of $13.2 \%$ among traumatic brain injury patients in their study. Among patients with mild head injuries in our study, favorable outcome was $94.34 \%$ and mortality was $3.77 \%$. Jacobs et al. [41] studied 2784 patients with mild traumatic brain injuries and found favorable outcome in $87 \%$ and mortality was $2 \%$. In our study, patients with moderate head injury had 95\% favorable outcome and 5\% mortality. In Hitimana et al. [40] the favorable outcome in moderate head injury was $75 \%$, while, in mild head injury, it was $100 \%$. Andriessen et al. [42] found that, in 169 moderate head injury patients in their study, the mortality was $17.68 \%$. Among patients with severe head injuries in our study, the favorable outcome was $52.17 \%$, while mortality was $39.13 \%$. Andriessen et al. [42] found mortality of $41.79 \%$ among 335 severe head injury patients in their study. Boto et al. [43] found that, in 895 patients with severe head injury they studied, the mortality was $46.8 \%$. In Hitimana et al. [40] study, the favorable outcome among severe head injury patients was $38.1 \%$. Wang et al. [44] in Taiwan found $86.6 \%$ mortality among severe head injury patients. From above studies, our outcome was within what had been documented in many series.

In our study, intracranial lesion did not significantly affect the outcome. Rudehill et al. [45] studied 1,500 patients and found that intracranial lesions did not affect the outcome significantly. However, Chastain et al. [46] studied both CT scan and MRI (T2 and flair) findings of their patients and found that CT scan findings did not predict the outcome but MRI findings predicted the outcome. Our finding was in keeping with their CT scan finding. That was because our patients did CT scan only as there was no MRI in our center and in our city. Nelson et al. [47] in 890 CT scans of traumatic brain injury studied found that extradural hematoma positively predicted outcome. In our study, patients with extradural hematoma had $100 \%$ favorable outcome. In contrast, patients with subdural hematoma had $63.64 \%$ favorable outcome and mortality of $27.72 \%$. In subdural hematoma, the impact is severe compared to extradural hematoma, and parenchymal injuries associated with subdural hematoma play major role in outcome determination. While we are heading towards zero mortality in acute extradural hematoma as predicted by Bricolo and Pasut [48], acute subdural hematoma outcome has not been encouraging. Wilberger Jr. et al. [49] found that, in 101 patients with acute subdural hematoma studied, the mortality was $66 \%$ and favorable outcome was $19 \%$. Lobato et al. [50] found that, in 64 patients with extradural hematoma they studied, the favorable outcome was $68.8 \%$, while the mortality was $28.1 \%$. They noted that mortality was restricted to those in coma. Ayub et al. [51] in 108 patients with acute extradural hematoma they studied found that the favorable outcome was $69 \%$ and mortality was $8 \%$. In 107 patients with extradural hematoma studied by Bricolo and Pasut [48], the favorable outcome was $89 \%$ and mortality was $5 \%$. In combined study of acute extradural and acute subdural hematoma by Taussky et al. [52], mortality among patients with acute subdural hematoma was $41 \%$, while those with acute extradural hematoma had 3\% mortality. These studies with our study showed marked improvement in outcome in extradural hematoma when compared with acute subdural hematoma.

\section{Conclusion}

Our study found that almost all motorcycle riders were not using crash helmet. We also found that the outcome was significantly related to severity of injury at presentation. Patients with acute extradural hematoma had better outcome than those with acute subdural hematoma.

We believe that reasons advocated by opponents of helmet use were not strong enough to outweigh the protective effects of helmet. We thus recommend that the Federal Road Safety Corps (FRSC) in our country should broaden riders' education and enforce road safety regulations and helmet use laws. Government should consider providing exclusive lanes for motorcycles in our cities.

\section{Conflict of Interests}

The authors declare that there is no conflict of interests regarding the publication of this paper.

\section{Authors' Contribution}

Concept and design are done by Dr. Mathias Ogbonna Nnanna Nnadi, Dr. Olufemi Babatola Bankole, and Dr. Beleudanyo Gbalipre Fente. Data acquisition and analysis are done by Dr. Mathias Ogbonna Nnanna Nnadi. Literature search, paper preparation, review, and final approval are done by Dr. Olufemi Babatola Bankole, Dr. Mathias Ogbonna Nnanna Nnadi, and Dr. Beleudanyo Gbalipre Fente. Guarantor is Dr. Mathias Ogbonna Nnanna Nnadi.

\section{Acknowledgment}

This study is supported by University of Calabar Teaching Hospital, Calabar, Cross River State, Nigeria.

\section{References}

[1] D. V. Hung, M. R. Stevenson, and R. Q. Ivers, "Prevalence of helmet use among motorcycle riders in Vietnam," Injury Prevention, vol. 12, no. 6, pp. 409-413, 2006.

[2] Ministry of Transport and Communication, Monthly Statistics of Transportation and Communications, Executive Yuan, Ministry of Transport and Communication, Taipei, Taiwan, 2005. 
[3] J. Zhang, R. Norton, K. C. Tang, S. K. Lo, Z. Jiatong, and G. Wenkui, "Motorcycle ownership and injury in China," Injury Control and Safety Promotion, vol. 11, no. 3, pp. 159-163, 2004.

[4] M. Penden, K. MeGee, and I. Sharma, The Injury Chart Book: A Graphical Overview of the Global Burden of Injuries, World Health Organization, Geneva, Switzerland, 2002.

[5] K. S. Oluwadiya, L. M. Oginni, A. A. Olasinde, and S. O. Fadiora, "Motorcycle limb injuries in a developing country," West African Journal of Medicine, vol. 23, no. 1, pp. 42-47, 2004.

[6] National Highway Traffic Safety Administration, Traffic Safety Facts 2005: Motorcycles, National Traffic Safety Administration, Washington, DC, USA, 2007.

[7] B. C. Liu, R. Ivers, R. Norton, S. Boufous, S. Blows, and S. K. Lo, "Helmets for preventing injury in motorcycle riders," Cochrane Database of Systematic Reviews, no. 1, Article ID CD004333, 2008.

[8] B. Jennett and M. Bond, "Assessment of outcome after severe brain damage," The Lancet, vol. I, no. 7905, pp. 480-484, 1975.

[9] J. T. King Jr., P. M. Carlier, and D. W. Marion, "Early Glasgow Outcome Scale scores predict long-term functional outcome in patients with severe traumatic brain injury," Journal of Neurotrauma, vol. 22, no. 9, pp. 947-954, 2005.

[10] I. W. Crandon, H. E. Harding, S. O. Cawich et al., "The impact of helmets on motorcycle head trauma at a tertiary hospital in Jamaica," BMC Research Notes, vol. 2, article 172, 2009.

[11] T. O’Keeffe, S. R. Dearwater, L. M. Gentilello, T. M. Cohen, J. D. Wilkinson, and M. M. McKenney, "Increased fatalities after motorcycle helmet law repeal: is it all because of lack of helmets?" Journal of Trauma, vol. 63, no. 5, pp. 1006-1009, 2007.

[12] M. Richter, D. Otte, U. Lehmann et al., "Head injury mechanisms in helmet-protected motorcyclists: prospective multicenter study," Journal of Trauma-Injury, Infection and Critical Care, vol. 51, no. 5, pp. 949-958, 2001.

[13] M.-M. Brandt, K. S. Ahrns, C. A. Corpron, G. A. Franklin, and W. L. Wahl, "Hospital cost is reduced by motorcycle helmet use," Journal of Trauma-Injury, Infection and Critical Care, vol. 53, no. 3, pp. 469-471, 2002.

[14] H. C. Nwadiaro, K. K. Ekwe, I. C. Akpayak, and H. Shitta, "Motorcycle injuries in north-central Nigeria," Nigerian Journal of Clinical Practice, vol. 14, no. 2, pp. 186-189, 2011.

[15] M. Khanbhal and M. B. I. Lutomia, "Motorcycle accident injuries seen at Kakamega provincial hospital in Kenya," East and Central African Journal of Surgery, vol. 17, pp. 43-46, 2012.

[16] A. U. Ekere and S. Ibeanusi, "Pattern of motorcycle associated injuries in Port-Harcourt: a hospital based study," Orient Journal of Medicine, vol. 16, pp. 36-40, 2003.

[17] B. A. Solagberu, C. K. P. Ofoegbu, A. A. Nasir, O. K. Ogundipe, A. O. Adekanye, and L. O. Abdur-Rahman, "Motorcycle injuries in a developing country and the vulnerability of riders, passengers, and pedestrian," Injury Prevention, vol. 12, no. 4, pp. 266268, 2006.

[18] G. T. Arosanyin, A. T. Olowosusu, and G. M. Oyeyemi, "Compliance with road safety regulations among commercial motorcyclists in Nigeria," Canadian Social Science, vol. 8, pp. 92-100, 2012.

[19] G. T. Arosanyin, "Are okada operators licensed to ride in Nigeria? A preliminary finding," in Proceedings of 14th Road Safety on Four Continents, Bangkok, Thailand, pp. 1179-1248, VTI, Linköping, Sweden, 2007.

[20] P. E. Iribhogbe and E. D. Odai, "Driver-related risk factors in commercial motorcycle (okada) crashes in Benin City, Nigeria,"
Prehospital and Disaster Medicine, vol. 24, no. 4, pp. 356-359, 2009.

[21] M. Fitzharris, R. Dandona, G. A. Kumar, and L. Dandona, "Crash characteristics and patterns of injury among hospitalized motorised two-wheeled vehicle users in urban India," $B M C$ Public Health, vol. 9, article 11, 2009.

[22] N. E. McSwain Jr. and A. Belles, "Motorcycle helmets: medical costs and the law," Journal of Trauma, vol. 30, no. 10, pp. 1189$1199,1990$.

[23] B. A. J. MacLeod, J. C. Digiacomo, and G. Tinkoff, "An evidencebased review: helmet efficacy to reduce head injury and mortality in motorcycle crashes: EAST practice management guidelines," Journal of Trauma, vol. 69, no. 5, pp. 1101-1111, 2010.

[24] G. Latorre, G. Bertazzoni, D. Zotta, E. Van Beeck, and G. Ricciardi, "Epidemiology of accidents among users of twowheeled motor vehicles: a surveillance study in two Italian cities," European Journal of Public Health, vol. 12, no. 2, pp. 99103, 2002.

[25] Y. Xuequn, L. Ke, R. Ivers, W. Du, and T. Senserrick, "Prevalence rates of helmet use among motorcycle riders in a developed region in China," Accident Analysis and Prevention, vol. 43, no. 1, pp. 214-219, 2011.

[26] J. Sreedharan, J. Muttappillymyalil, B. Divakaran, and J. C. Haran, "Determinants of safety helmet use among motorcyclists in Kerala, India," Journal of Injury \& Violence Research, vol. 2, no. 1, pp. 49-54, 2010.

[27] M. Ali, M. M. S. Saeed, M. M. Ali, and N. Haidar, "Determinants of helmet use behaviour among employed motorcycle riders in Yazd, Iran based on theory of planned behaviour," Injury, vol. 42, no. 9, pp. 864-869, 2011.

[28] M. Aare and H. von Holst, "Injuries from motorcycle and moped crashes in Sweden from 1987-1999," Injury control and safety promotion, vol. 10, no. 3, pp. 131-138, 2003.

[29] M.-R. Lin and J. F. Kraus, "A review of risk factors and patterns of motorcycle injuries," Accident Analysis and Prevention, vol. 41, no. 4, pp. 710-722, 2009.

[30] J. Mayrose, "The effects of a mandatory motorcycle helmet law on helmet use and injury patterns among motorcyclist fatalities," Journal of Safety Research, vol. 39, no. 4, pp. 429-432, 2008.

[31] European Commission, Saving 20,000 Lives on Our Roads: A Shared Responsibility, Office for the Official Publications of European Communities, Luxembourg City, Luxembourg, 2003.

[32] B. O. Adegbehingbe, K. S. Oluwadiya, and O. O. Adegbehinde, "Motorcycle associated ocular injuries in Ile-Ife, Nigeria," African Journal of Trauma, vol. 2, pp. 35-39, 2004.

[33] P. F. Umebese and S. U. Okukpo, "Motorcycle accidents in a Nigeria University campus: a one year study of pattern of trauma sustained in the University of Benin," Nigerian Journal of Clinical Practice, vol. 10, pp. 33-36, 2001.

[34] E. T. Owoaje, O. E. Amoran, O. Osemeikhain, and O. E. Ohnoferi, "Incidence of road traffic accidents and pattern of injury among commercial motorcyclists in a rural community in South Western Nigeria," Journal of Community Medicine and Primary Health Care, vol. 17, no. 1, pp. 7-12, 2005.

[35] P. Siviroj, K. Peltzer, S. Pengpid, and S. Morarit, "Helmet use and associated factors among thai motorcyclists during Songkran festival," International Journal of Environmental Research and Public Health, vol. 9, no. 9, pp. 3286-3297, 2012.

[36] W. Swaddiwudhipong, C. Boonmak, P. Nguntra, and P. Mahasakpan, "Effect of motorcycle rider education on changes 
in risk behaviours and motorcycle-related injuries in rural Thailand," Tropical Medicine and International Health, vol. 3, no. 10, pp. 767-770, 1998.

[37] R. S. Radin-Umar, "Motorcycle safety programmes in Malaysia: how effective are they?" International Journal of Injury Control and Safety Promotion, vol. 13, no. 2, pp. 71-79, 2006.

[38] A. Agrawal, C. S. Agrawal, A. Kumar, O. Lewis, G. Malla, and P. Chalise, "Head injury at a tertiary reerral centre in the Eastern Region of Nepal," East and Central African Journal Surgery, vol. 14, no. 1, pp. 57-63, 2009.

[39] I. Muhammad, "Management of head injuries at the ABU hospital, Zaria," East African Medical Journal, vol. 67, no. 6, pp. 447-451, 1990.

[40] J. Hitimana, M. Perez, A. Kinasha, and I. Kakande, "Clinical presentation and outcome of neurosurgical conditions at Butare teaching hospital, Rwanda," East and Central African Journal Surgery, vol. 14, no. 1, pp. 50-56, 2009.

[41] B. Jacobs, T. Beems, M. Stulemeijer et al., "Outcome prediction in mild traumatic brain injury: age and clinical variables are stronger predictors than CT abnormalities," Journal of Neurotrauma, vol. 27, no. 4, pp. 655-668, 2010.

[42] T. M. J. C. Andriessen, J. Horn, G. Franschman et al., "Epidemiology, severity classification, and outcome of moderate and severe traumatic brain injury: a prospective multicenter study," Journal of Neurotrauma, vol. 28, no. 10, pp. 2019-2031, 2011.

[43] G. R. Boto, P. A. Gómez, J. De La Cruz, and R. D. Lobato, "Severe head injury and the risk of early death," Journal of Neurology, Neurosurgery and Psychiatry, vol. 77, no. 9, pp. 1054-1059, 2006.

[44] Y. C. Wang, F. K. P'eng, D. Y. Yang et al., "Epidemiological study of head injuries in central Taiwan," Zhonghua Yi Xue Za Zhi (Taipei), vol. 55, no. 1, pp. 50-57, 1995.

[45] A. Rudehill, B.-M. Bellander, E. Weitzberg, S. Bredbacka, M. Backheden, and E. Gordon, "Outcome of traumatic brain injuries in 1,508 patients: impact of prehospital care," Journal of Neurotrauma, vol. 19, no. 7, pp. 855-868, 2002.

[46] C. A. Chastain, U. E. Oyoyo, M. Zipperman et al., "Predicting outcomes of traumatic brain injury by imaging modality and injury distribution," Journal of Neurotrauma, vol. 26, no. 8, pp. 1183-1196, 2009.

[47] D. W. Nelson, H. Nyström, R. M. MacCallum et al., "Extended analysis of early computed tomography scans of traumatic brain injured patients and relations to outcome," Journal of Neurotrauma, vol. 27, no. 1, pp. 51-64, 2010.

[48] A. P. Bricolo and L. M. Pasut, "Extradural hematoma: toward zero mortality. A prospective study," Neurosurgery, vol. 14, no. 1, pp. 8-12, 1984.

[49] J. E. Wilberger Jr., M. Harris, and D. L. Diamond, "Acute subdural hematoma: morbidity, mortality, and operative timing," Journal of Neurosurgery, vol. 74, no. 2, pp. 212-218, 1991.

[50] R. D. Lobato, J. J. Rivas, F. Cordobes et al., "Acute epidural hematoma: an analysis of factors influencing the outcome of patients undergoing surgery in coma," Journal of Neurosurgery, vol. 68, no. 1, pp. 48-57, 1988.

[51] S. Ayub, M. Ali, and M. Ilyas, "Acute extradural haematoma: factors affecting the outcome," Journal of Postgraduate Medical Institute, vol. 19, no. 2, pp. 208-211, 2005.

[52] P. Taussky, H. Widmer, J. Takala, and J. Fandino, "Outcome after acute traumatic subdural and epidural haematoma in Switzerland: a single-centre experience," Swiss Medical Weekly, vol. 138, no. 19-20, pp. 281-285, 2008. 

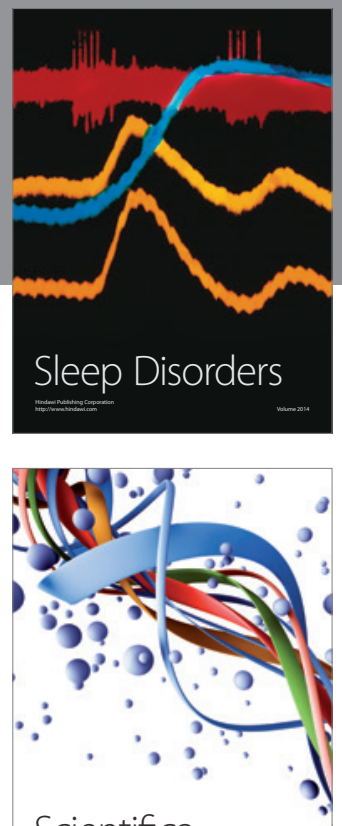

Scientifica
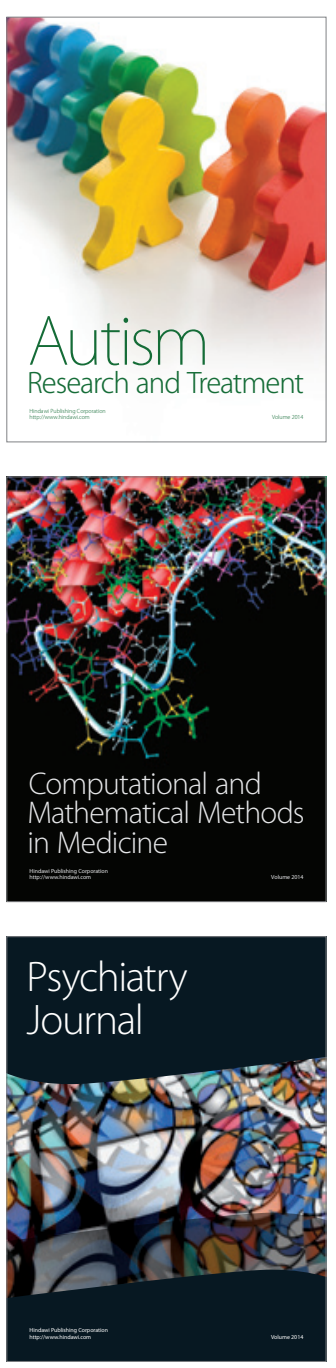
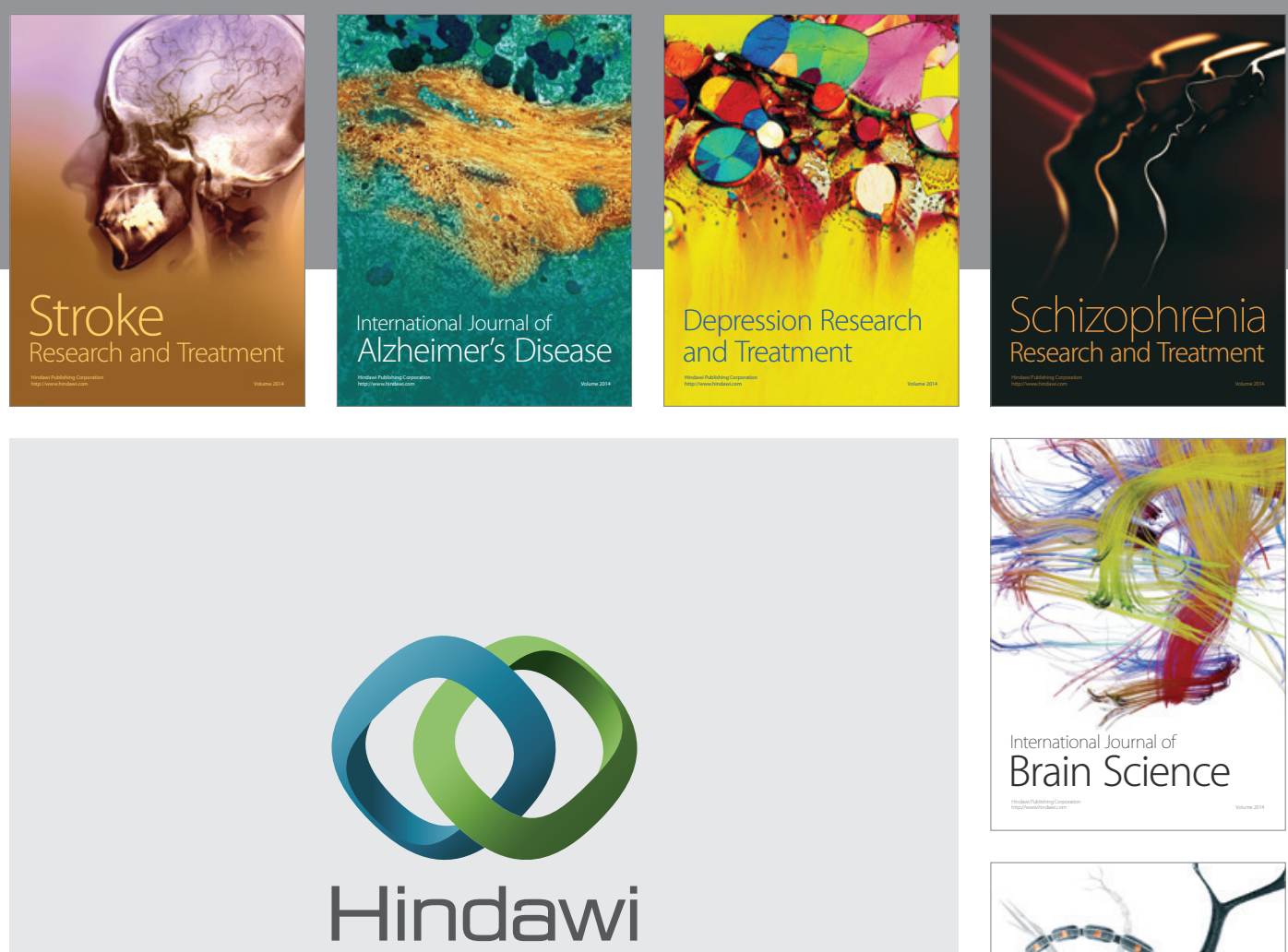

Submit your manuscripts at

http://www.hindawi.com
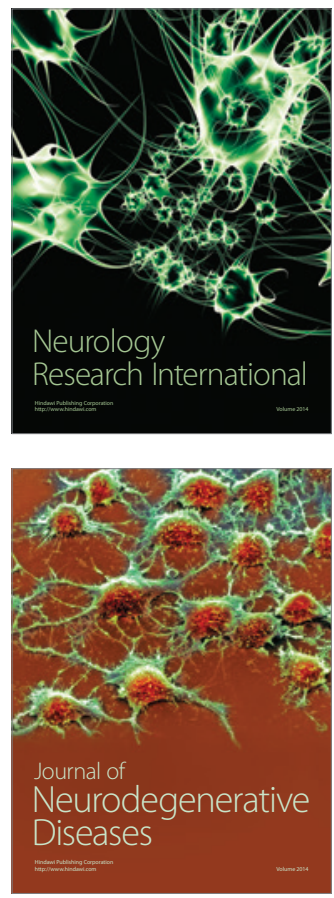

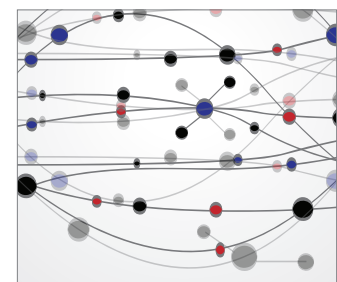

The Scientific World Journal
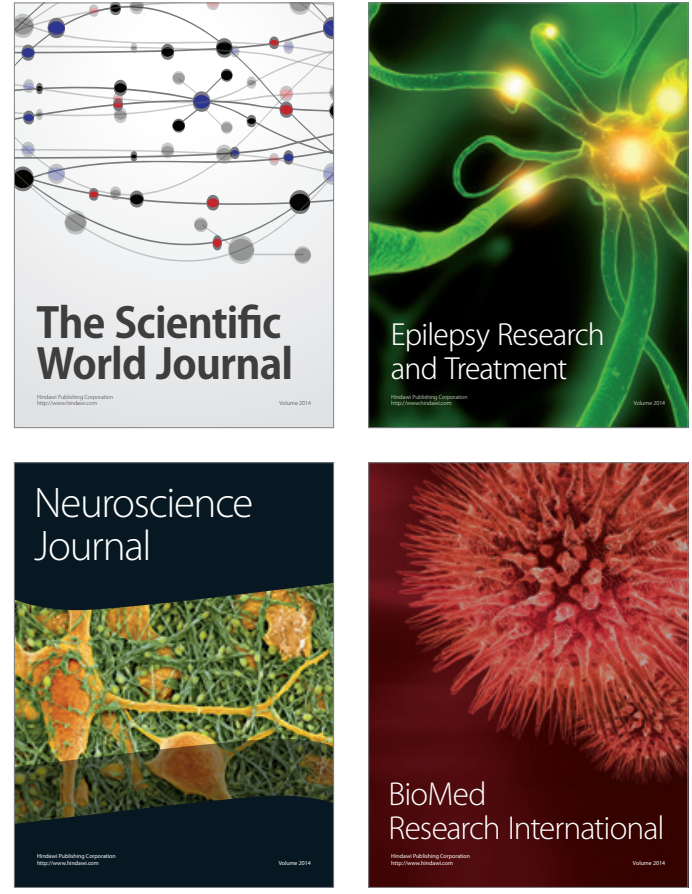

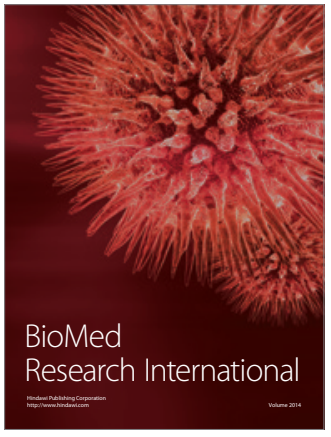

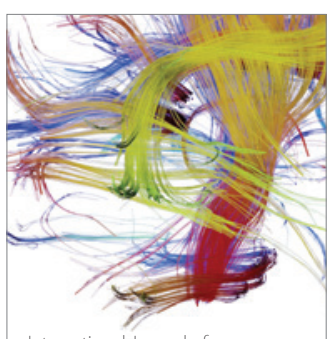

Brain Science

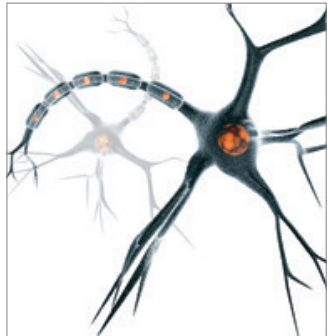

Neural Plasticity
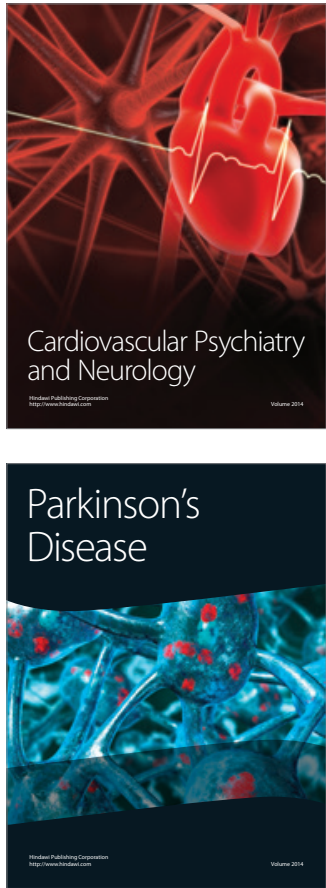